\title{
Образование, занятость и досуг как факторы миграции молодёжи из малых городов
}

71\% всех городов России - это малые города (на 2020 г. их численность составляет 794 из 1117).Однако нынешняя ситуация в малых городах характеризуется неблагоприятными показателями социально-экономической и социально-демографической сферы, чрезвычайно ограниченными возможностями развития и занятости молодёжи. Происходящие на региональном и локальном уровнях социально-экономические проблемы, связанные с образованием, трудоустройством, здравоохранением, культурным развитием, воплощаются в самые разнообразные следствия в форме усиливающейся мобильности, перемещений, миграционных настроений, особенно молодого поколения. Наблюдаемый отток молодежи в региональные центры, крупные города значительно уменьшает человеческий и социальный потенциал малого города, сужает перспективы развития. Возможности выбора более качественных условий проживания, образования и трудоустройства служит источником мобильности молодёжи различных регионов. Причём, как отмечает О.В. Аксёнова, "данная проблема характерна для многих российских сёл и малых городов. В мегаполисах больше возможностей работы, заработка, больше различных кружков и секций для детей, есть больницы в шаговой доступности, а не в соседнем селе или вовсе региональном центре и т. п.". [1, с. 47].

Проблемам молодёжной миграции уделяется много внимания в научной литературе. Многолетние социологические исследования о проблемах жизненных планов молодёжи, досуга, фрормирования мировоззрения, молодёжного предпринимательства, демографическим и миграционным вопросам, концептуальному оформлению молодёжной политики представлены в монографии М.К. Горшкова, Ф.Э. Шереги [2]. Кроме того, ряд исследователей молодёжную миграцию связывают в первую очередь с получением образования и трудоустройством [8; 9], а также наличием культурно-досугового пространства [4].

Научное исследование, проведенное сотрудниками ФНИСЦ РАН в рамках темы "Регионы в социальном пространстве России: центростремительные и центробежные тенденции" в 2019 году, ставило одной из своих целей разобраться в причинах оттока молодого поколения, условиях существования молодежи малых городов, их участии и активности в жизни родного города. С этой целью изучались социально-экономические, культурные ресурсы малых городов, наличие инфраструктуры, оказывающие благоприятное воздействие на жизнь молодёжи. Полевая часть исследования проходила в 21 малых городах (шесть из которых моногорода) ${ }^{1}$. Причём в каждом макрорегионе отбор

1 В исследование вошли города Лихославль и Кимры (Тверская область), Сокол и Красавино (Вологодская область), Аксай и Миллерово (Ростовская область), Изобильный и Новоалександровск (Ставропольский край), Балахна и Заволжье (Нижегородская область), Среднеуральск и Ирбит (Свердловская область), Шелехов и Зима (Иркутская область), Большой Камень и Спасск-Дальний (Приморский край), Красный (Смоленская область), Лиман и Харабали (Астраханская область), Суоярви и Костомукша (Республика Карелия).

(C) Роговая А. В., Левченко Н. В., 2020

РОГОВАЯ Анастасия Владимировна, канд. социол. наук, старший научный сотрудник Центра региональной социологии и конфликтологии Института социологии Федерального научно-исследовательского социологического центра PAН (2. Москва). E-mail: av_rogovaya@mail.ru

ЛЕВЧЕНКО Наталья Валерьевна, научный сотрудник Центра политологии и политической социологии Института социологии Федерального научно-исследовательского социологического центра PAH (2. Москва). E-mail: natalya_levchenk@mail.ru 
проводился таким образом, чтобы один малый город входил в состав агломерации, а другой являлся локализованным. Были проведены глубинные экспертные интервью по анкете с 96 экспертами - представителями муниципальной власти, бизнеса, НКО, ассоциаций и профсоюзов, молодёжных объединений, а также 32 фокус-группы (по 8-12 человек в каждой) с представителями бизнес-сообществ и гражданского общества.

К числу главных причин миграции молодёжи из малых городов эксперты относят необходимость получения образования, возможность более перспективного трудоустройства и достойного уровня заработной платы, отсутствие инфраструктуры, низкий уровень досуга и невозможность профрессиональной реализации на сформированном рынке труда, а также неблагоприятная экологическая обстановка. Кроме того, существенное влияние оказывает информация, которую молодёжь получает из интернета. Там прослеживаются чёткие установки на успешную и комдортную жизнь, потребительское поведение и на жизнь в большом городе. Таким образом, к основным видам миграционных процессов молодёжи можно отнести: образовательную, трудовую и экономическую миграцию. Приведенные причины оттока молодёжи подтверждаются результатами российских исследований, на основе которых изучалась зависимость миграции от социально-экономических фракторов на уровне отдельных муниципальных образований [6].

Поскольку по итогам проведенного научного исследования сферы образования, трудоустройства, здравоохранения, культуры и досуга имеют значительные ограничения с точки зрения удовлетворения потребностей и реализации интересов молодёжи, авторами были выделены основные виды миграций молодежи из малых городов: образовательная, трудовая и связанная с отсутствием досуга, условий для самореализации/саморазвития.

\section{Образовательная миграция}

Большую роль в перераспределении молодого населения между городами разных типов играет образовательная миграция. Значимый приток молодёжи в межрегиональной миграции имеют крупнейшие столичные города, притягивающие учебных мигрантов со всей страны или концентрирующих их в пределах отдельных макрорегионов (Москва, Санкт-Петербург, Новосибирск, Томск, Хабаровск, Воронеж и др.) [5, с. 48]. Современные исследователи отмечают, что миграция молодёжи тесно связана с возможностью получения доступных и разнообразных образовательных услуг [10]. Одной из причин такой миграции в крупные города и другие агломерации является недостаток или отсутствие учреждений средне-специального и высшего образования в малых городах. Как показывают различные исследования, для молодёжи образование - это абсолютная ценность, способствующая её социально-культурному развитию. Кроме того, молодёжь стремится получить бюджетное средне-специальное и высшее образование, рассматривая его в качестве инвестиций в будущее профессиональное развитие. В этом случае региональные центры предоставляют на порядок больше возможностей, связанных с реализацией образовательных и профессиональных стратегий. В этой связи важным для молодого человека является возможность получения должного и качественного образования или его повышения на местном уровне.

Однако в малых городах, где проводились исследования, практически нет вузов или их филиалов. Поскольку решение вопросов образования в малом городе находятся в сфере региональной ответственности, соответственно, местная власть зачастую не имеет возможности поддерживать филиалы государственных вузов, поэтому даже в тех городах, где были ссузы и фрилиалы вузов, многие из них были закрыты.

При этом следует отметить, различную специфику малых городов в зависимости от их территориального расположения, точнее удаленности от регионального центра. В городах-агломерациях, находящихся недалеко от регионального центра, в большинстве случаев есть средне-специальные учебные заведения или вузы и их фрилиалы. Даже если и отсутствуют учебные заведения, то молодёжь свободно ездит в центр, чтобы получить образование. Допустим, у выпускника школы в г. Большой Камень Приморского края, где только один вуз - филиал Дальневосточного федерального университета, или 
моногорода Красавино, где нет ни одного вуза, а до ближайшей Вологды - 475 км. И как отмечают участники фокус-группы, в городе Красавино, с одной стороны, есть хорошие условия для обучения детей дошкольного и школьного возраста, с другой стороны, нет возможности продолжать обучение: "учиться негде, высшее образование, даже специальное у нас не получишь, только школа..." (участник фрокус-группы 1 - далее УФГ). Участники опроса указали, что ранее в городе находилось профессиональное училище, однако в дальнейшем его закрыли: "былл колбинат, соответственно сразу же было проббессиональное училище, которое готовило вот эти кадры, и молодёжь была здесь, они учились ... очень много народу было и приток был молодёжи тоже, из соседних регионов приезжали", "сейчас профбессионального образования здесь нет, но многие хотели бы вернуться после учебных заведений... поэтолу проблема большая" (УФГ1).

Сложнее обстановка в локализованных малых городах, где зачастую закрылись как филиалы высших учебных заведений, так и техникумы, колледжи. К примеру, в локализованном городе Ирбит Свердловской области после окончания школы молодёжь может продолжить учебу только в средне-специальных учебных заведениях. Как отмечает эксперт: "У нас раньше были gбилиальь двух вузов это УПИ и Государственный институт колмериии и права. Сейчас эти ббилиаль не работают. Ну и конечно в средне-специальных учебных заведениях возможности тоже ограничены, потолу что спектр специальностей тал не такой большой" (Э1). Как отмечает представитель бизнеса, "в своё вреля, когда работал завод... было всё задействовано...два техникула работали, чтобы ковать свои кадры. Потол в последствии сделали фбилиал Тюленского института, готовили специалистов для завода. Когда всё это развалилось, всё это стало невостребовано" (УФГ2).

Причем молодёжь из таких локализованных городов, уезжая в другие города для получения высшего образования, как правило, не возвращается обратно.

По мнению экспертов, в малом городе, находящемся далеко от регионального центра, обязательно нужны средне-специальные заведения или филиал вуза: "нал нужен технический университет, и он у нас был, его закрыли ... у нас было, по-лоелу, пять специальностей: айтишники, лотор, технология машиностроения, в общел технологии, конструкторы... и у нас все выпускники были трудоустроены до окончания вуза!" (Э2).

Ситуация в малых городах-агломерациях несколько лучше за счёт наличия учебных заведений среднего и высшего образования, что является хорошим показателем инфраструктуры. Но, даже имея возможность получить образование в родном городе, молодёжь всё равно стремится в региональный центр или любой другой крупный город. Как отмечают эксперты г. Балахны Нижегородской области, молодёжь как раньше из деревень бежала в город, так сейчас из малых городов молодые люди тянутся в областной центр. "Тем более, что сал фбакт того, что Балахна находится в 30 минутах езды, конечно же, она утягивает лолодёжь отсюда" (ЭЗ).

Так, в г. Шелехов Иркутской области есть и техникум, и колледж, и фрилиал Иркутского техникума архитектуры и строительства, но, поскольку рядом Иркутск, молодёжь продолжает учебу там или в другом крупном городе, как Ангарск, Усолье, где также есть филиалы высших учебных заведений. С одной стороны, близость малого города к областному центру даёт преимущества, потому что те молодые люди, которые заканчивают школу, поступая ввузы, могут оставаться жить дома и спокойно ездить. С другой стороны, таким образом теряется активная молодёжь, которая большую часть времени проводит в центре и в дальнейшем там же устраивается на работу. Такая маятниковая миграция характерна для городов-агломераций.

В городе-агломерации Сокол Вологодской области есть педагогический колледж и техникум, но, по мнению экспертов, необходим фоллиал вуза. "У нас есть хорошие преподаватели, где можно на базе колледжа...сделать фбилиал пединститута, и дети будут оставаться, по крайней мере, с учителями, проблелу мь решим. Тоже салое на базе техникула. ... База есть. Даже есть общежития, где люди будут жить" (Э4). 
Помимо желания самой молодёжи покинуть малый город, многие родители не хотят, чтобы их дети жили здесь и стараются отправить своих детей в центр или другой крупный город, чтобы они смогли получить образование и в дальнейшем остаться там. Семьи готовы оказывать весомую поддержку своим детям для переезда в крупный город.

Таким образом, в малых городах преимущественно остаются лишь те, кто плохо учился - двоечники и троечники, в большинстве своем это дети из неблагополучных семей. Именно они поступают в местные колледжи и техникумы, либо не продолжают обучение. Возвращается молодёжь в малые города после окончания учебы, если только есть наличие хорошего рабочего места, или в связи с неудачным опытом обустройства в крупном городе.

Молодёжь, которая имеет способности в учебе, после окончания высшего заведения старается остаться в крупном городе или региональном центре. Это большая проблема на уровне муниципалитетов, поскольку тех специалистов, которые вернулись и работают после окончания вуза в малых городах достаточно мало.

Хотя, как эксперты отмечают, система школьного образования в малых городах достаточно хорошо развита, "очень много ребят с золотылии медалями заканчивают школу, поступают в высшее учебное заведение, но не возвращаются обратно из-за низкой инфбраструктуры, из-за того, что с жильёл проблель" (Э5).

Кроме вышеперечисленного существует и общая проблема, связанная с образованием, - это установка на получение высшего образования. В связи с чем дети неохотно идут учиться в техникумы и колледжи, не считая данное образование престижным. "Человека пьтаются запихнуть в институт, он получает образование институтское, считает себя супер-инженером, но в итоге без опьта работы он николу не нужен и он с больщим трудом и желаниел потол идёт работать слесарел, хотя елу налного проще было бы отучиться в техникуле" (Э6). Данная установка также способствует ликвидации техникумов в малых городах: "у нас в середине года закрылся фбилиал Петрозаводского колледжа технологии и предпринилательства, т.к. в течение трёх лет был недобор. У нас должны были обучаться 150 студентов, а поступали только 50" (Э7).

Процессы миграции молодёжи приводят к негативным последствиям и существенно влияют на развитие малого города. И если в ходе исследований "Роль структур гражданского общества в социальных процессах современной России" в 2013-2015 гг. мы часто сталкивались с тем, что не все выпускники стремились покинуть свой малый город, многие хотели вернуться в свой город после обучения: "y нас всегда есть работа для выпускников-инженеров, у нас требуются ветеринары, механизаторы, в результате проиентов 70-80 учашихся возвращаются обратно" (Э8). То в последующие годы ситуация значительно ухудшилась. Как показало исследование, в большинстве случаев молодёжь не возвращается в "родной регион" для того, чтобы реализовать полученные знания или профессиональные навыки.

\section{Трудовая миграция}

Занятость молодёжи после окончания учёбы - это один из актуальных вопросов на сегодняшний день. Отсутствие реальной возможности трудоустройства в родном городе - серьёзный фрудамент для устойчивого оттока молодёжи из малых городов. Как следует из материалов әкспертных интервью и фокус-групп, многие ориентированы на выезд из города в целях трудоустройства, получения достойной заработной платы.

Ограниченные возможности рынка труда и ресурсной базы малых городов России заставляет молодёжь уезжать в региональный центр. Это видно по статистике: идёт большой отток молодёжи из муниципальных образований в силу отсутствия возможности трудоустройства после получения профессионального среднего или высшего образования.

По мнению экспертов, причины этому разные: во-первых, низкий уровень социальной сфреры, во-вторых, оптимизация предприятий и производства и, в-третьих, низкая заработная плата. 
Немного лучше обстоит ситуация в городах с градообразующими и другими крупными предприятиями. Так, помимо рабочих мест, предполагается, что у них есть возможность уделять внимание социальной сфере. Таким образом, некоторые крупные предприятия могут оказывать влияние на миграционные настроения молодёжи, занимаясь социальной политикой в отношении своего персонала. Однако на сегодняшний день всё меньшее внимание уделяется данному вопросу. Так, например, ранее Заволжский моторный завод много сил вкладывал в развитие сфреры образования и здравоохранения, культуры и спорта. Между тем ситуация изменилась: "проблела не только нашего города касается, а всех моногородов - это взаилный конфбликт интересов между градообразующил предприятиел и городом. Поэтому они не заинтересовань совершенно в настоящел серьезно работать, наприлер, с человеческил капиталол, то есть с молодёжью" (Э9).

Градообразующие предприятия, заводы - это самая крупная точка опоры для малых городов. С одной стороны, существование только градообразующего и отсутствие других промышленных предприятий означает полную зависимость городского населения от такого предприятия [7, c. 161]. С другой - наличие крупного производства не всегда удерживает молодёжь, многие всё равно стремятся переехать в более крупный город или областной центр. В то же время в город с крупным производством легче вернуться, так как есть возможность найти работу. $К$ примеру, Заволжье Нижегородской области - технический, промышленный город, и, как отмечают эксперты, часть молодых людей возвращаются обратно: "мы не охватьваел всех работой, но многие же возвращаются. Они не приживаются в больших городах, не могут платить за квартиры, создалась селья - нет детских садов" (Э2).

Иная ситуация обстоит в малых городах, где нет крупных производств и предприятий. В связи с тем, что развитие города в большей мере зависит от их наличия, по мнению экспертов, для того чтобы молодёжь приезжала и оставалась в родном малом городе, необходимо думать о том, чтобы в таких городах были предприятия регионального или федерального значения. Например, в городе Зима Иркутской области нет градообразующего предприятия, это в основном частный сектор, где весомый процент населения составляют неблагополучные семьи, а перспективы трудоустройства молодёжи есть только на железной дороге или в ближайшем городе Саянске. "И если лы говорил про рабочие специальности - ничего больше нет... Большое предприятие наше РЖД, кроле того "Байкал-Форест" - тоже большое предприятие, но тем не менее, молодёжь не трудоустроена" (Э10).

Большинство малых городов, удаленных от центра экономической активности, не могут предоставить достаточную альтернативу занятости молодёжи. Поэтому для городов, находящихся далеко от регионального центра, характерен маятниковый метод миграции, а также вахтовая миграция. Как отмечают эксперты г. Красавино, половина трудоспособного населения города, в том числе молодёжи, работают вахтовым методом, уезжая на 2-4 месяца за пределы города.

Кроме того, региональный центр остается значительно привлекательным. Так, например, г. Ирбит Свердловской области, по мнению экспертов, по отношению к другим муниципалитетам более интересен и самодостаточен, есть крупные заводы, какие-то инвестиции, но молодое поколение всё равно предпочитает уезжать в Екатеринбург и Тюмень. В г. Шелехов Иркутской области есть условия трудоустройства на заводе, но, по мнению экспертов, там "очень мальй процент работает иленно на заводах" (УФГЗ),"илея в городе два крупных завода, молодежь все равно уезжает в Иркутск и зачастую maлn оседает" (Э11), молодёжь уезжает в центр либо в Новосибирск, либо в Красноярск.

Возникла и другая проблема, если согласно указа Президента РФ от 7 мая 2012 г. № 597 "О мероприятиях по реализации государственной социальной политики" существенно подняли зарплату бюджетникам: врачам, учителям, - то простые профессии, которые участвуют в производстве (токарь, сварщик и др.), оказались на другом уровне - как низкооплачиваемые "Молодёжь у нас считает, что они после институтов и на станок не пойдут, поэтолу с меньшил желаниел идут на станок" (Э6).Так, на сегодняшний день 
из-за такого перекоса г. Ирбит Свердловской области испытывает кадровый голод рабочих профессий.

Также одной из причин нехватки сотрудников на предприятиях в малых городах является установка молодёжи - "получать лного денег не напрягаясь", которую диктует интернет-сообщество, что в свою очередь порождает специфическую форму безработицы. Отмечено, что некоторые жители малых городов и посёлков предпочитают одноразовые услуги, позволяющие какое-то время прожить на заработанные деньги. [1, с. 47-48]. И, несмотря на кадровый голод в г. Ирбит, по статистике показатели коэфорициента безработицы там выше среднего. "Либо та зарплата, которая есть, может быть их не устраивает. Они ишут где лучше" (Э12). Как отмечает представитель бизнеса г. Зима Иркутской области, в городе есть работа, в центре занятости много вакансий, однако молодёжь там не хочет работать, "потолу что проще быть долушникали ... нету стрелления больше зарабатывать...Париклахерь никто не пошел никуда. Двадиать два человека выпустилось на повара... в школах нету повара..." (УФГ4).

Таким образом, по данным исследования, можно отметить, что миграция молодёжи может проходить следующие этапы:

Первый этап - семья живёт в малом городе, ребёнок учится там в школе до 9-го класса, далее, если есть возможность, там же он получает среднее образование, если нет, то переезжает либо вся семья, либо отправляют ребёнка на обучение.

Второй этап - если в населённом пункте нет вузов или средне-специальных учебных заведений, то, соответственно, молодой человек с целью дальнейшего обучения вынужден переезжать в областной центр или другой город. Третий этап - переезд после окончания вуза в связи с поиском работы.

Так, если нет рабочих мест по той специальности, которую молодой человек получил, то он вынужден либо устраиваться на работу не по профилю, либо уехать из города. Как правило, места локации - крупные города, областные центры, Москва, Санкт-Петербург.

Как показало исследование, в том случае, когда малый город обладает трудовым, инвестиционным, энергетическим и природным потенциалом для него всё равно характерен отток молодёжи.

Таким образом, существует несколько причин трудовой миграции молодёжи:

1. Нет перспективы для развития. По мнению участников фрокус-группы г. Сокол Вологодской области, молодёжь здесь не задерживается, потому что они не видят перспективы. С другой стороны, представитель бизнеса г. Сокола отмечает, что работы много: "Я готов набрать, молодёжь не хотят работать, ил надо большие зарплать. А у нас другая проблема-они не хотят руками работать" (УФГ5).

2. Молодые люди не хотят идти на производство, "хотят работать гдето дола или на машинах кататься, вот это у всех" (Э2).

3. Ограниченность направлений профессиональной деятельности для молодёжи.

4. Низкий уровень заработной платы. В г. Зима Иркутской области изза низкооплачиваемых рабочих мест молодёжь уезжает на вахту в другой город, "тал живут какое-то определенное время, ... приезжают потол, соответственно привозят деньги, до выпивки начинают...." (УФГ6). Вследствие этого в городе много неблагополучных семей: "уровень жизни в Зиме оставляет желать лучшего... все молодье едут в Иркутск, Красноярск" (УФГ7). Для г. Заволжье Нижегородской области характерна челночная миграция, когда молодёжь из города уезжает за более высокими зарплатами в Городец и Балахну, а в Заволжье приезжают работать с соседних муниципальных образований. "То есть сюда приток, будел говорить, неквалифбиированной рабочей силь и челночная миграция квалифицированных специалистов" (Э13).

5. Требование опыта при устройстве на работу. Как отмечает әксперт из г. Ирбит Свердловской области, "прольщленное производство у нас оно наполнено тели кадрали, которые уже с многолетнил стажел, опытные люди, молодёжи устроиться некуда" (Э5). 
Эксперты опять же вспоминали, что раньше была поддержка молодому специалисту, были подъёмные, жильё и работа. По мнению одного из экспертов, "есть проблель, когда молодыл специалистам и приезжил специалистали выдавали служебное жильё с возложностью приватизации через сель лет, что являлось очень важныл фбакторол для выбора леста работы... но в итоге ил говорили, что не ложете её приватизировать. Кто потол захочет сюда ехать?" (Э14).

Необходимо отметить и другие социально-экономические проблемы малых городов в России: высокая зависимость в экономическом плане от регионального бюджета, невыгодные конкурентные позиции в сравнении со средними и крупными городами в привлечении квалифицированных кадров и инвестиционного капитала, низкий уровень развития здравоохранения и образования, недостаточно развитая социально-культурная сфера и низкий уровень развития инфраструктурных объектов.

\section{Досуг}

Важным фрактором миграции молодого поколения является отсутствие разнообразного досуга, а также слабо развитая культурная и развлекательная сфера молодёжи. По мнению экспертов, чтобы удержать молодого специалиста в малом городе, недостаточно повысить зарплату, необходимо также наличие развитой инфраструктуры, мест для развлечения детей, проведения личного досуга и т.п.

Как показало исследование, в малых городах активно ведётся работа по формированию досуга для молодёжи. При этом властные структуры в основном уделяют внимание организации досуга в сфрере спорта в связи с проведением фредеральных, региональных программ, направленных на развитие физической культуры и спорта. По мнению экспертов, наиболее активно принимают участие в жизни родного города школьники и студенты, но когда они заканчивают вуз, то работать в основном уезжают в центр, поэтому малый город теряет основную активную молодёжь.

Поэтому в процессах регулирования оттока молодёжи важно ориентироваться на её потребности и мотивации, важно организовывать досуг для самореализации активной молодёжи и удержанию ее в малом городе. Если молодые люди будут востребованы, получат перспективы самореализации в сегодняшней сложной жизни, то будет дан дополнительный импульс социально-экономическому развитию малого города, а молодёжь обретёт жизненные надежды - это и есть основной способ преодоления негативных явлений в молодёжной среде.

На основе создания культурно-досугового пространства в процессе взаимодействия среднего, высшего и дополнительного образования формируется культура досуга молодёжи [3, с. 55]. По данным исследования, в малых городах хорошо развиты образовательные учреждения дополнительного образования. К примеру, в Ирбит Свердловской области, по словам экспертов, очень хорошие спортивная и музыкальная школы. "У нас молодёжь очень способная. В областных конкурсах занилают и побеждают первые места... у нас проводится ежегодно школа бизнеса, и молодёжь предоставляет такие бизнес-проекты, которые не каждый предпринилатель сможет написать" (УФГ8). В школах г. Шелехов Иркутской области открываются профильные классы: "в свое вреля был даже класс РУСАЛов, класс ИркАЗа, где дети получали знания, уления, и потол дальше шли по этолу же направлению в металлургии, наприлер. Сейчас тоже открываются разного рода клас$\mathrm{cbl}$, даже тот же класс МВД" (Э11).При этом, как отмечают участники фрокус-группы г. Зима и г. Кимры, нет материально-технической базы для работы дополнительных кружков и секций.

Но в большинстве случаев, несмотря на все усилия, прилагаемые в этой сфрере, уровень обеспечения культурного досуга противоречит потребностям и интересам молодого поколения: "лы создавали, всю жизнь работали ради того, ... чтоббы наши дети, по крайней мере, как мы гордились, как старшее поколение, этил городол. К сожалению, такой уверенности сегодня нет... потолу что у нас перспектив нет" (УФГ9) 
В отличие от крупных городов и областных центров, в малых городах, особенно локализованных, нет такого разнообразия культурной жизни для молодого поколения в силу отсутствия должного финансирования. Конечно, в районных центрах сохранились дома культуры, библиотеки и учреждения дополнительного образования, но, как правило, все они держатся благодаря сотрудникам-энтузиастам.

Как отмечает представитель молодёжной организации г. Заволжье Нижегородской области, не хватает досуга в сфере культуры: "... у нас вообще ничего нет, абсолютно. ...если говорил досуг, есть платные кружки, но помимо этого для молодёжи, которье не ходят на кружки, то нечел заняться...В сравнении с Городиол, в которол все мероприятия районного масштаба, проходят фбейерверки, хороводы, шикарно, у нас бюджета на это нет... У нас люди на праздники перестали ходить, потолу что у нас скукотища" (УФГ10). Даже отсутствие кинотеатра в г. Аксай, по мнению эксперта, "это молодёжная проблема. Это действительно проблела, потолу что некуда девать себя вечерами" (УФГ11).

Кроме того, молодежь в малых городах старается принимать участие в общественных объединениях. Проблема в том, по мнению экспертов, что активным развитием молодёжи занимаются не молодежные организации, не администрация в рамках молодёжной политики, а отдельные активисты.

Хотя, по мнению экспертов, потенциал у молодёжи из малых городов есть значительный. "У нас очень талантливая молодёжь. Залечательные школьники, ледалистов очень лного, тех, у кого высокие балль за экзалены. И возложность получения дополнительного образования у нас залечательная в городе есть. ... Здесь у нас как бы есть возложности. В городе нужно над этил работать..." (Э12).

\section{Выводы}

Отток молодёжи как проблема признается всеми экспертами. С одной стороны, миграция молодого поколения способствует приобретению знаний, умений, трудовых навыков, увеличению доходов и платежеспособности этого слоя населения. С другой стороны, активная молодёжь не возвращается в родной город и не инвестирует приобретенные ресурсы в развитие малого города. Как показало исследование, складываются устойчивые направления миграции молодёжи: в малые города приезжают молодые люди из ближайших сел и деревень, а молодёжь из малых городов старается переехать в региональный центр, столицы или близлежащий крупный город. Кроме того, сложились реальные миграционные связи между городами, поселениями. Например, жители малых городов ездят на работу в соседние города (например, из Кимр и Лихославля в Тверь и Москву) или живут в сельской местности, а работать едут в малый город. Молодежь, по мнению әкспертов, конечно, уезжает, но, уехав в другие города, она возвращается, не потому что ей хочется сюда вернуться, а потому что в большом городе людям, не имеющих каких-то определенных возможностей, труднее зацепиться.

По мнению большинства экспертов, опорными для России должны оставаться малые города, поскольку именно в таких маленьких городах воспитываются дети, они берут модель, образ жизни, поведения от своих родителей и едут в крупные города строить большую политику, заводы и фабрики, "mo есть всё, что даст мальий город - то мы увидим в нашел будущем поколении" (Э15).

Таким образом, для молодёжи должна быть создана комфортная среда для проживания. Для того чтобы молодые люди оставались на своей малой родине и способствовали ее развитию, необходимо создание условий для экономического, социального и культурного развития города. Как указывают эксперты, государство должно взять на себя ответственность за трудоустройство молодых людей.

По мнению экспертов, нужны инвестиции на любые производства, поскольку трудоустройство возникает именно из инвесторов, все взаимосвязано. Государственная политика управления развитием малых городов в регионах должна концентрироваться на следующем: 
во-первых, обеспечить доступ молодёжи к среднему и высшему профрессиональному образованию;

во-вторых, способствовать развитию инфраструктуры для воспроизводства качественного кадрового потенциала развития города, восстановлению, сохранению и развитию городских предприятий;

в-третьих, обеспечить перевод налогов в местный бюджет, поскольку, по мнению экспертов, весь развал города пошел с определенного момента, когда поменялось налоговое законодательство, когда пошел отток денег, "задыххаются те же салье школь, медицина, образование";

в-четвертых, способствовать сохранению и развитию "своей уникальности" малых городов.

Необходимо учитывать и отдаленность населённого пункта от областного центра, и изношенность инфраструктуры.

Малые города нуждаются в другой модели экономики страны. Тем городам, которые не имеют градообразующие или крупные предприятия, необходимо поддерживать самостоятельные рынки сбыта, генерировать самостоятельные рабочие места в виде малого, среднего бизнеса. Малым городам-агломерациям же необходимо обеспечить развитие предприятий, увеличить количество рабочих мест, поднять заработную плату. По данным исследования, малым городам необходимо также выстраивать связи с большими близлежащими городами, развивать инфраструктуру удобной для доступности, что даст новый виток для их развития.

Если говорить о влиянии государства в социальном направлении, здесь требуется изменения, дальнейшие действия в сфере школьного, дополнительного и дошкольного образования детей.

Кроме того, необходимо изменить отношение молодёжи к перспективе жизни в малом городе. Сейчас считается не престижным оставаться в малом городе, четко прослеживается влияние идеологии развития, ориентированной на большой город, часто не помогает даже предоставленное жильё и деньги. $[1$, c. 49].

Таким образом, только при условии заинтересованности государства в развитии малых городов с научно-образовательными и культурными центрами, транспортной доступностью и обеспеченностью населения системой здравоохранения, созданием рабочих мест и не в угоду корпоративным предприятиям, а для развития территорий страны, можно говорить о благоприятных перспективах.

\section{Список информантов}

Э1Мужчина; муниципальное управление; общественный помощник Уполномоченного; г. Ирбит;

Э2 Женщина; муниципальное управление; глава администрации; г. Заволжье;

Э3 Мужчина; муниципальное управление; депутат; г. Балахна

Э4 Мужчина; муниципальное управление; руководитель администрации; г. Сокол;

Э5 Женщина; муниципальное управление; заместитель главы администрации; г. Ирбит;

Э6 Мужчина; бизнес; г. Балахна;

Э7 Женщина; муниципальное управление; глава Суоярвского городского поселения;

Э8 Мужчина; муниципальное управление; глава муниципального образования "Краснинский район" Смоленской области; Э9 Женщина; СМИ; журналист; г. Заволжье;

Э10 Мужчина; гражданское общество; председатель городского совета ветеранов; г. Зима;

Э11 Женщина; гражданское общество; директор Благотворительного фонда местного сообщества имени Григория Шелехова; г. Шелехов;

Э12 Женщина; муниципальное управление; депутат; г. Ирбит;

Э13 Мужчина; муниципальное управление; глава МСУ, г. Заволжье; Э14 Мужчина; бизнес; г. Зима; 
Э15 Женщина; СМИ; директор информационного центра; г. Зима УФГ1 Женщина; бизнес; г. Красавино;

УФГ2 Мужчина; бизнес; г. Ирбит; УФГз Мужчина; бизнес; г. Шелехов; УФГ4 Женщина; бизнес; г. Зима; УФГ5 Мужчина; бизнес; г. Сокол;

УФГ6 Женщина; гражданское общество; г. Зима; УФГ7 Мужчина; гражданское общество; г. Зима;

УФГ8 Женщина; бизнес; г. Ирбит; УФГ9 Мужчина; бизнес; г. Шелехов;

УФГ10 Женщина; гражданское общество; молодежная организация; г. Заволжье;

УФГ11 Женщина; бизнес; г. Аксай.

\section{Литература}

1. Аксёнова О.В. Субъект социального действия в современном развитии России: агент, актор, никто // Вестник Института социологии. 2020. Т. 11. № 2. С. 37-53.

2. Горшков М.К., Шереги Ф.Э. Молодежь России в зеркале социологии. К итогам многолетних исследований: [монография] / М.К. Горшков, Ф.Э. Шереги. М: ФНИСЦ PAH, 2020. 688 c.

3. Еманова С.В., Хомутникова Е.А. Дополнительное образование детей и взрослых как фактор формирования досуговой культуры студенческой молодёжи // Мир науки, культуры, образования. 2018. № 6 (73). С. 55-56.

4. Зубок Ю.А., Чупров В.И. Молодежь в культурном пространстве: саморегуляция жизнедеятельности: монография / Ю.А. Зубок, В.И. Чупров. М.: Норма, 2020. $304 \mathrm{c}$.

5. Маркин В.В., Малышев М.Л., Землянский Д.Ю. Малые города России: комплексный мониторинг развития. Часть 1. // Мониторинг правоприменения. 2019. № 4. C. $46-55$.

6. Мкртчян Н.В. Миграция молодёжи из малых городов России // Мониторинг общественного мнения: әкономические и социальные перемены. 2017. № 1 (137). C. $225-242$.

7. Пахомова О.А. Агломерации как инструмент решения проблем миграции молодёжи //Развитие территориальных социально-экономических систем: вопросы теории и практики. Сборник научных статей XV Международной научно-практической конференции молодых учёных. Ответственный редактор Ю.Г. Лаврикова. 2017. C. $160-163$.

8. Российская молодежь в динамике десятилетий. Статистические материалы и результаты исследований: [монография] / [Д.Л. Константиновский, Г.А. Чередниченко и др.]. М.: ИС РАН, 2017. 190 с. С. 54-77.

9. Рязанцев С.В. Современная миграционная политика России: проблемы и подходы к совершенствованию // Социологические исследования. 2019. №9. С. 117-126.

10. Федорова А.В., Хорольцева Е.Б. Межрегиональная миграция молодёжи в условиях реализации стратегии развития Саратовской области//Вестник Поволжского института управления. 2020. Т. 20. № 1. С. 73-82.

\section{Транслитерация по ГОСТ 7.79-2000 Система Б}

1. Aksyonova O.V. Sub"ekt sotsial'nogo dejstviya $\mathrm{v}$ sovremennom razvitii Rossii: agent, aktor, nikto // Vestnik Instituta sotsiologii. 2020. T. 11. № 2. C. 37-53.

2. Gorshkov M.K., SHeregi F.EH. Molodezh' Rossii v zerkale sotsiologii. K itogam mnogoletnikh issledovanij: [monografiya] / M.K. Gorshkov, F.EH. SHeregi. M: FNISTS RAN, 2020.688 s.

3. Emanova S.V., KHomutnikova E.A. Dopolnitel'noe obrazovanie detej i vzroslykh kak faktor formirovaniya dosugovoj kul'tury studencheskoj molodyozhi // Mir nauki, kul'tury, obrazovaniya. 2018. № 6 (73). S. 55-56.

4. Zubok YU.A., CHuprov V.I. Molodezh'v kul'turnom prostranstve: samoregulyatsiya zhiznedeyatel'nosti: monografiya / YU.A. Zubok, V.I. CHuprov. M.: Norma, 2020. 304 s.

5. Markin V.V., Malyshev M.L., Zemlyanskij D.YU. Malye goroda Rossii: kompleksnyj monitoring razvitiya. CHast' 1. // Monitoring pravoprimeneniya. 2019. № 4. S. 46-55.

6. Mkrtchyan N.V. Migratsiya molodyozhi iz malykh gorodov Rossii // Monitoring obshhestvennogo mneniya: ehkonomicheskie i sotsial'nye peremeny. 2017. № 1 (137). S. 225-242.

7. Pakhomova O.A. Aglomeratsii kak instrument resheniya problem migratsii molodyozhi //Razvitie territorial'nykh sotsial'no-ehkonomicheskikh sistem: voprosy teorii i praktiki. Sbornik nauchnykh statej XV Mezhdunarodnoj nauchno-prakticheskoj konferentsii molodykh uchyonykh. Otvetstvennyj redaktor YU.G. Lavrikova. 2017. S. 160-163. 
8. Rossijskaya molodezh' v dinamike desyatiletij. Statisticheskie materialy i rezul'taty issledovanij: [monografiya] / [D.L. Konstantinovskij, G.A. CHerednichenko i dr.]. M.: IS RAN, 2017. 190 s. S. 54-77.

9. Ryazantsev S.V. Sovremennaya migratsionnaya politika Rossii: problemy i podkhody k sovershenstvovaniyu // Sotsiologicheskie issledovaniya. 2019. № 9. C. 117-126.

10. Fedorova A.V., KHorol'tseva E.B. Mezhregional'naya migratsiya molodyozhi v usloviyakh realizatsii strategii razvitiya Saratovskoj oblasti//Vestnik Povolzhskogo instituta upravleniya. 2020. T. 20. № 1. S. 73-82.

Роговая А. В., Левченко Н. В. Образование, занятость и досуг как факторы миграции молодёжи из малых городов.

В малых городах регионов России одной из острых проблем является отток молодёжи в региональные центры и крупные города. В статье использованы результаты экспертного интервью и опроса фокус-групп в 21 российских малых городах. Проведен сравнительный анализ сложившейся ситуации, связанной с миграционными процессами в малых городах-агломерациях и в локализованных городах, расположенных на большом расстоянии от региональных центров. В ходе исследования были рассмотрены основные виды миграций молодёжи из малых городов: образовательная, трудовая и связанная с отсутствием досуга, выделены этапы трудовой миграции. Рассмотрены основные причины и направления оттока молодого поколения. В работе анализируются возможности и препятствия возвратной миграции, а также пути минимизации оттока молодёжи.

Ключевые слова: образовательная миграция, трудовая миграция, досуг, молодёжь, малый город

Rogovaya A. V., Levchenko N. V. Education, employment and leisure as factors of youth migration from small towns.

An urgent problem in small towns of Russian is the outflow of youth to regional centers and large cities. The article uses the results of an expert survey and focus groups in 21 Russian small towns. A comparative analysis of the migration processes situation related to in small agglomeration towns and in localized towns located at a great distance from regional centers is carried out. The study examined the main types of youth migration from small towns: educational, labor and related to lack of leisure. The main reasons and directions of the outflow of youth are considered. The article analyzes the possibilities and obstacles of return migrationand minimize ways the outflow of youth.

Key words: educational migration, labor migration, leisure, youth, small town

Для цитирования: Роговая А. В., Левченко Н. В. Образование, занятость и досуг как факторы миграции молодёжи из малых городов // Ойкумена. Регионоведческие исследования. 2020. № 4. C. 23-33. DOI: 10.24866/1998-6785/2020-4/23-33

For citation: Rogovaya A. V., Levchenko N. V. Education, employment and leisure as factors of youth migration from small towns // Ojkumena. Regional researches. 2020. № 4. P. 23-33. DOI: $10.24866 / 1998-6785 / 2020-4 / 23-33$ 